\title{
Práticas articulatórias em contextos organizacionais: discursos do cooperativismo de crédito rural solidário em Minas Gerais
}

Articulatory practices in organizational contexts: discourses of solidary rural credit cooperativism in Minas Gerais

Prácticas de articulación en contextos organizacionales: discursos del cooperativismo de crédito rural solidario en Minas Gerais

Márcia Eliana Martins

- $\quad$ Professora do Instituto Federal de Educação, Ciência e Tecnologia Baiano (IF Baiano).

- Coordenadora do curso superior de Tecnologia em Gestão de Cooperativas do IF Baiano.

- $\quad$ Doutora em Extensão Rural pela Universidade Federal de Viçosa (UFV).

- $\quad$ Mestre em Desenvolvimento Rural pela Universidade Federal do Rio Grande do Sul (UFRGS).

- E-mail: me.martins2010@gmail.com

(9) Rennan Lanna Martins Mafra

- Doutor em Comunicação Social pela Universidade Federal de Minas Gerais (UFMG).

- $\quad$ Professor do Departamento de Comunicação Social UFV.

- $\quad$ Orientador no Programa de Pós-Graduação em Comunicação da Universidade Federal de Juiz de Fora (UFJF).

- $\quad$ Orientador no Programas de Pós-Graduação em Educação da UFV.

- $\quad$ Líder do Grupo de Pesquisa em Discursos e Estéticas da Diferença (DIZ).

- $\quad$ E-mail: rennan.mafra@ufv.br 


\section{Resumo}

Este artigo examina como a cooperação e a solidariedade são tensionadas em práticas articulatórias nos contextos organizacionais do cooperativismo de crédito rural solidário, a partir da investigação de campos discursivos da cooperativa Cresol Tombos, em Minas Gerais. Por meio da análise do discurso da comunicação organizacional, o texto aponta, como resultados, a figuração de campos discursivos que promovem articulações da cooperação e da solidariedade com lógicas de instituições financeiras tradicionais, opostas aos princípios fundantes das cooperativas de crédito rural solidário.

\section{PALAVRAS-CHAVE: DISCURSO•COOPERATIVISMO DE CRÉDITO SOLIDÁRIO •COMUNICAÇÃO ORGANIZACIONAL・RURAL.}

\section{Abstract}

From the discursive fields of Cresol Tombos cooperative in Minas Gerais, this article examines the tension between cooperation and solidarity in articulation practices within organizational contexts of solidary-based rural credit cooperatives. The discourse analysis of the organizational communication indicates the presence of discursive fields that articulate cooperation and solidarity with logics of traditional financial institutions, opposed to the core principles of solidarity rural credit cooperatives.

KEYWORDS: DISCOURSE・SOLIDARY CREDIT COOPERATIVES•ORGANIZATIONAL COMMUNICATION・RURAL.

\section{Resumen}

Para contribuir con la comunicación organizacional mediante estudios del discurso y de mediatización, este artículo pretende actualizar la comprensión acerca de las relaciones públicas. Con base en investigación bibliográfica, se argumenta que los modelos funcionalistas y lineales no bastan para abarcar la complejidad de los procesos de comunicación en sociedades mediatizadas o en proceso de mediatización y se concluye que, dado que la circulación es el área de disputa y negociación de significados por excelencia, la misma debería ganar relevancia en trabajos sobre gestión de conflictos entre actores sociales. 


\title{
INTRODUÇÃO
}

0

campo do cooperativismo de crédito rural solidário, no Brasil, mostra-se atravessado por inúmeras tensões, como podemos perceber no trecho:

\begin{abstract}
Pesquisadora: Como é que o senhor define uma cooperativa de crédito rural solidária? 0 que o senhor acha que deveria ser uma cooperativa de crédito rural solidária?
\end{abstract}

Entrevistado: 0 que que eu acho que deve ser uma cooperativa de crédito...

Pesquisadora: Rural solidária.

Entrevistado: Rural solitária? Rural quer dizer, eu moro na zona rural. Solitária quer dizer o que? Desculpe da pergunta.

Pesquisadora: Solidária, de solidariedade.

Entrevistado: Ah, solidariedade... (silêncio). Ah faz de novo, que eu...

Pesquisadora: Como é que o senhor define uma cooperativa de crédito?

Entrevistado: Olha, como eu defino uma cooperativa de crédito? Ah, uma cooperativa de crédito é uma coisa que é mais fácil da gente conseguir um empréstimo, é mais fácil da gente, é... ter mais tempo de conversar com as pessoas do crédito... é, ah só isso, por enquanto!.

Nele, o entrevistado - um agricultor - busca compreender a expressão discursiva (rural solidária) que caracteriza a cooperativa de crédito da qual faz parte para, a partir disso, construir uma resposta ao questionamento. 0 fato de tal agricultor não conseguir articular uma explicação precisa é gesto que traz à tona um mundo complexo de significados presentes no cooperativismo de crédito rural solidário, para o qual nosso olhar se volta atentamente neste artigo.

Quando as cooperativas de crédito solidárias surgiram na Zona da Mata de Minas Gerais, o contexto em que os agricultores envolvidos em seu processo de fundação estavam inseridos ligava-se diretamente aos movimentos sociais da região e aos Sindicatos dos Trabalhadores Rurais (Martins, 2016). Nesse sentido, essas organizações procuraram instituir práticas de funcionamento e atendimento baseadas nas necessidades de seus cooperados, moldando sua atuação no que se refere à prestação de seus serviços, de acordo com as especificidades do grupo de agricultores que as constituíram. Entretanto, dadas as exigências legais via Banco Central do Brasil (BSB), em determinado ponto de sua história, tais cooperativas foram confrontadas em um contexto pouco favorável para a sua continuidade enquanto instituições financeiras solidárias, procurando, assim, novas alternativas de funcionamento que as viabilizassem economicamente sem prejudicar seu objetivo social. Assim, uma das alternativas encontradas pelas cooperativas de crédito rural solidárias juridicamente vinculadas à Cresol Tombos - organização que será analisada neste trabalho - foi a incorporação de suas organizações ao Sistema de Cooperativas de Crédito Rural com Interação Solidária (Cresol), o mais consolidado entre os sistemas de crédito rural solidário do país. Essa incorporação entre os sistemas trouxe para o cotidiano dos agricultores associados novas práticas organizacionais a partir da importação forçada de novas

1 Depoimento oral de um associado da Cresol Tombos, Espera Feliz, 2015. 
padronizações de seus processos internos. Nesse momento, com a alteração de aspectos normativos, o cooperativismo de crédito rural solidário viu-se permeado por outros significados em seus campos discursivos.

Dessa forma, partindo das perspectivas teóricas de Laclau e Mouffe (1987) e de Baldissera (2007, 2009, 2014), nosso objetivo, neste artigo, é examinar como a cooperação e a solidariedade são mobilizadas em campos discursivos do cooperativismo de crédito rural solidário no momento de sua incorporação forçada pela legislação brasileira, tomando como realidade investigativa uma das cooperativas vinculadas ao Sistema Cresol, na Zona da Mata de Minas Gerais. De modo mais específico, pretendemos apresentar práticas articulatórias (Laclau; Mouffe, 1987) que emergem na interação entre o campo discursivo autorizado - da "organização comunicada", aquele representado pelo Sistema Cresol, sua base regional e a direção da própria cooperativa, que trazem, em seu bojo, os ditames e as normativas do Banco Central do Brasil - e o campo discursivo que aqui denominamos desautorizado - da "organização comunicante" (Baldissera, 2009), representado aqui pelos agricultores associados no âmbito dessa cooperativa e de suas unidades.

Sendo assim, este artigo está dividido em quatro partes, além desta introdução, que objetivam apresentar: 1) um breve panorama do cooperativismo de crédito no Brasil; 2) uma aproximação conceitual entre a Teoria do Discurso de Laclau e Mouffe (1987) e a noção de comunicação organizacional em Baldissera (2009); 3) os procedimentos metodológicos adotados; e 4) uma análise de práticas articulatórias, com vistas a compreender como a incorporação ao Sistema Cresol afetou os campos discursivos do cooperativismo de crédito rural solidário, tendo como pano de fundo empírico a Cresol Tombos, localizada na Zona da Mata de Minas Gerais.

\section{REFERENCIAL TEÓRICO}

A compreensão dos modos como a cooperação e a solidariedade são mobilizadas em campos discursivos do cooperativismo de crédito rural solidário, a partir da investigação empírica do momento de sua incorporação motivada pelo BCB, é gesto que solicita, antes de tudo, dois movimentos teóricos: um, voltado a compreender a complexidade organizacional do cooperativismo de crédito no Brasil - no qual inseriram-se tentativas de produção de um tipo de crédito solidário, destinado a contextos rurais; e outro voltado a problematizar como tal complexidade organizacional pode ser examinada por uma lente analítica do discurso.

Perseguindo tais movimentos teóricos, a mobilização conceitual deste texto divide-se em dois fragmentos, dispostos a seguir: breves comentários sobre o cooperativismo de crédito no Brasil e discurso e comunicação organizacional: a construção de uma lente analítica.

\section{Breves comentários sobre o cooperativismo de crédito no Brasil}

As cooperativas ${ }^{2}$ de crédito surgiram num contexto em que muitos sujeitos não conseguiam ter acesso a serviços bancários por meio das instituições financeiras existentes (Bittencourt, 2001; Búrigo, 2006). Desse modo, a finalidade de tais organizações foi guiada pelo estabelecimento de instrumentos que possibilitassem o acesso ao crédito e a outros produtos financeiros por seus associados, despertando-lhes o sentido de poupança e concedendo-lhes empréstimos a juros abaixo dos praticados pelas instituições financeiras tradicionais. Ainda que tenham surgido como uma proposta alternativa a tais instituições,

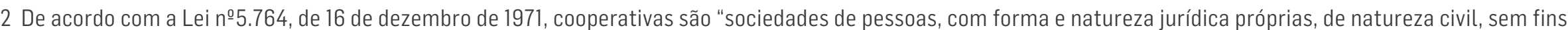

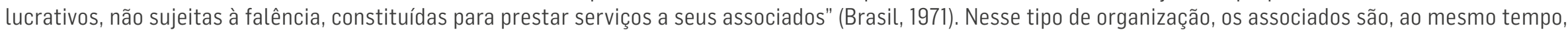

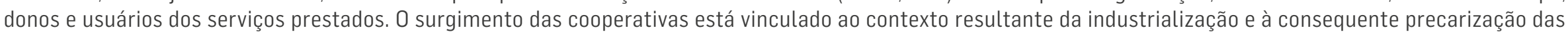

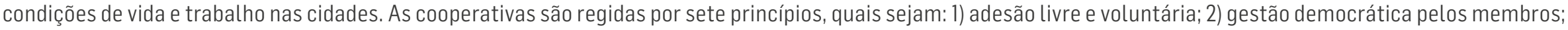
3) participação econômica dos membros; 4) autonomia e independência; 5) educação, formação e informação; 6) intercooperação; 7) interesse pela comunidade. 
através da Lei n0.595, de 31 de dezembro de 1964 (Brasil, 1964)³), as cooperativas de crédito foram legalmente equiparadas às instituições financeiras (Bittencourt, 2001). Essa classificação legal imputou, a algumas cooperativas, lógicas de atuação que as aproximavam dos bancos comerciais, contribuindo para que outros públicos permanecessem à margem do sistema financeiro, tal como os agricultores menos capitalizados.

Dessa forma, instituíram-se, no Brasil, as cooperativas de crédito rural solidárias, com a proposta de oferecer, àquela parcela de agricultores excluídos, o acesso ao crédito e a serviços que não eram obtidos por meio dos bancos comerciais ou das cooperativas tradicionais, devido às garantias financeiras exigidas - valor mínimo de renda mensal, documentos que comprovassem a posse de imóveis e, principalmente, prazos e juros exigidos para o pagamento - condições que esses agricultores dificilmente conseguiriam cumprir.

No que tange ao campo do cooperativismo de crédito rural solidário no Brasil, havia vários sistemas representativos até 2008 - Cooperativa Central de Crédito e Economia Solidária (Ecosol); Cooperativa Central de Crédito Rural com Interação Solidária (Cresol); Associação das Cooperativas de Apoio à Economia Familiar (Ascoob); Cooperativa de Crédito Rural dos Pequenos Agricultores e da Reforma Agrária (Crehnor); Cooperativa de Crédito Rural de Desenvolvimento Solidário de lúnaES (Credsol), além de outras cooperativas singulares não vinculadas a sistemas representativos -, congregados em uma associação nacional, a Associação Nacional do Cooperativismo de Crédito de Economia Familiar e Solidária (Ancosol), cuja atuação se restringia ao âmbito estadual ou regional (Freitas, 2011).

Contudo, na interpretação do sistema financeiro nacional, essa variedade de interesses e formas de atuação presentes no campo do cooperativismo de crédito solidário contribuiu para que essas organizações fossem vistas como frágeis, "apesar de serem organizações formadas [em sua maioria] por agricultores familiares e com propósitos sociais" (Freitas; Freitas, 2013, p.1009). Diante das dificuldades que enfrentavam para "alcançar sua legitimidade perante os órgãos regulatórios externos e outras organizações com as quais interagem" (Freitas; Freitas, 2013, p.1009), foi constituída, em 2008, a Confederação das Cooperativas Centrais de Crédito Rural com Interação Solidária (Confesol), visando reorganizar esse campo e congregar sistemas e cooperativas singulares, com o argumento de se fortalecerem perante o sistema financeiro nacional.

Essa reorganização dizia respeito à orientação geral do BCB para que as cooperativas de crédito estivessem vinculadas a um sistema organizador, pois, no entendimento daquele órgão, o pertencimento "a um sistema traz mais segurança" às cooperativas, lhes permitindo "adotar o padrão de estrutura e funcionamento" desse sistema, através do compartilhamento de "normas internas, sistemas de controles, procedimentos, tecnologia, produtos, serviços e marca" (Soares; Balliana, 2009, p.23). Para esses autores, a ligação formal a um sistema imputaria às cooperativas uma melhoria "na prestação de serviços e no relacionamento com os associados, bem como nos controles organizacionais e sistêmicos" (Soares; Balliana, 2009, p.23).

Entretanto, a vinculação forçada a uma confederação provocou novos arranjos nas práticas interacionais locais entre agricultores e cooperativas de crédito rurais solidárias (Martins, 2016). Nessa seara, novos significados também passaram a ser articulados em meio ao discurso da cooperação e da solidariedade - marcas identitárias estruturantes de tais organizações. De tal sorte, a teoria do discurso de Laclau e Mouffe (1987) e a noção de comunicação organizacional de Baldissera (2007, $2009,2014)$ oferecem um conjunto relevante à construção de uma lente analítica, voltada ao exame de tal realidade, conforme será apresentado a seguir. 


\section{Discurso e comunicação organizacional: a construção de uma lente analítica}

Discurso é uma categoria que, segundo Laclau e Mouffe (1987), congrega não só as palavras, mas também as ações dos sujeitos num dado contexto histórico e cultural. É a partir do discurso que "o social deve ser percebido" (Mendonça, 2009, p.155) como um campo, ou seja, como um espaço discursivo caracterizado por um "sem número" de significados. A admissão de um só centro constituidor das identidades não pode ser aceita, pois as sociedades contemporâneas são portadoras de múltiplos centros em que procedem inúmeras identidades emergentes que disputam o significado da realidade (Ferreira, 2011). Assim, "o campo do social é uma guerra de trincheiras, de estabelecimento de espaço" (Ferreira, 2011, p.14), em que determinados grupos buscam significados de acordo com os seus interesses. Ainda que esses grupos logrem alcançar seu intento, qualquer significado é parcial e provisório, visto que sempre existirão outros significados a compor o quadro das relações sociais.

O discurso, nessa perspectiva, "é um sistema de representação, cuja função é a produção de sentidos, com o intuito de simbolizar a realidade sob um conjunto de significados articulados". É, assim, aberto, pois atrai "elementos de outras formações discursivas, vinculando-os à sua própria rede de significação" (Silva, 2014, p. 202) e constitui-se através do que Laclau e Mouffe (1987) denominam como prática articulatória, uma vez que "uma estrutura discursiva não é uma entidade meramente 'cognoscitiva' ou 'contemplativa', é uma prática articulatória que constitui e organiza as relações sociais" (Laclau; Mouffe, 1987, p.161-162, tradução nossa).

Dessa forma, a prática articulatória deriva da articulação, ou seja, um artifício que "estabelece uma relação entre elementos, cuja identidade resulta modificada como resultado dessa prática". Elementos, por sua vez, representam "toda diferença que não se articula discursivamente", mas que, em uma dada construção discursiva - como quando diferentes grupos se unem em torno de uma reivindicação comum - poderão ser reduzidos a momentos ou "às posições diferenciais que aparecem articuladas no interior de um discurso" (Laclau; Mouffe, 1987, p.176-177, tradução nossa). Esses momentosacontecem quando a articulação discursiva ocorre entre diferentes campos, cujos sentidos possuem, como ligação, pontos nodais-epicentros em que sentidos se fixam parcial e provisoriamente na estrutura discursiva, projetando um contexto minimamente estável. Entretanto, o discurso resultante da união desses campos discursivos não é homogêneo; pelo contrário, contém em si as demandas particulares, bem como as contradições e os antagonismos dos sujeitos que o compõem.

Figura 1: Representação gráfica do discurso a partir da perspectiva de Laclau e Mouffe (1987)

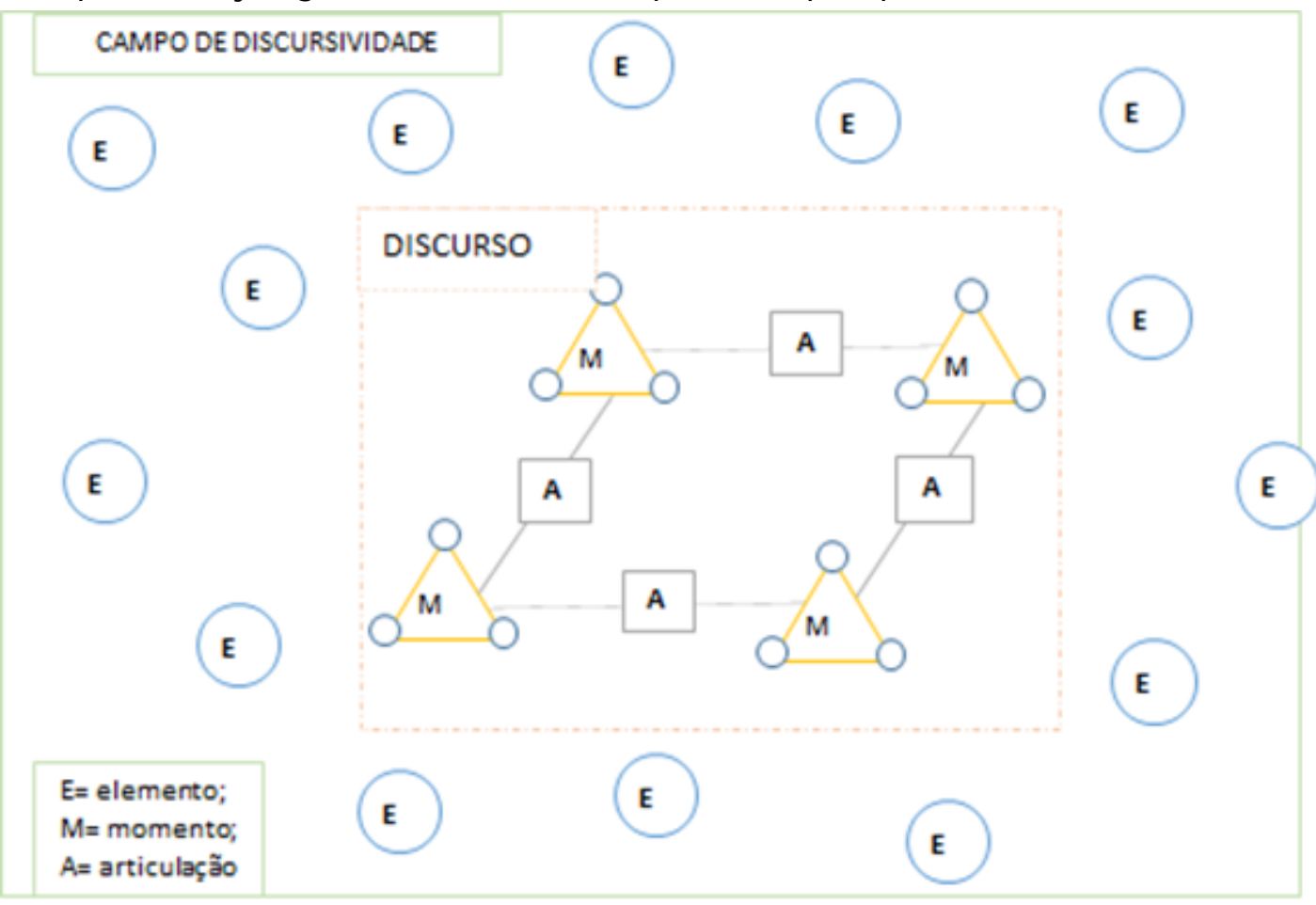

Fonte: Elaborado pelos autores a partir de Ferreira (2011) 
Nesse sentido, o discurso é uma construção social que procura "conferir significado à realidade a partir de alguns sentidos"; no entanto, será sempre uma construção "instável" que "está em permanente disputa" (Silva, 2014, p.203). Tal instabilidade ocorre justamente porque os sentidos produzidos por um discurso, além de precários e contingentes, são limitados por outros discursos exteriores, produtores de sentidos que lhes são contrários e que, por isso, não permitem que um discurso seja "finalístico". Assim, a expansão de sentidos de um dado discurso é bloqueada "pela presença de seu corte antagônico", ou seja, pela "impossibilidade da constituição de um sentido objetivo, ou finalístico, a toda lógica discursiva" (Mendonça, 2009, p.161). Ainda que o antagonismo represente um limite à construção discursiva, ele indica igualmente sua "própria condição de existência" (Mendonça, 2009, p.161), visto que é por essa condição antagônica que os significados continuamente serão questionados, levando à necessidade de serem repensados.

Dessa forma, é possível ponderar em que medida práticas articulatórias - que buscam reunir identidades diferentes em torno de uma proposta comum - emergem nos contextos das organizações. Para Baldissera (2007, p. 240), a construção e a transformação da identidade organizacional acontecem no processo de interação entre sujeitos e organizações, visto que esses sujeitos "não nascem com as identidades dos grupos a que pertencem". Essa identidade vai sendo moldada no relacionamento entre os objetivos particulares e os objetivos comuns que uniram os sujeitos em organizações e é nesse ínterim que se torna possível aos sujeitos conhecer "a significação do que seja ser membro de um determinado grupo cultural, seu lugar na estrutura social e as regras e normas que definem como deve portar-se frente ao 'outro'", por meio do conjunto de significação que representa o grupo (Baldissera, 2007, p.240). Em relação a isso, Baldissera (2014, p.9) afirma que embora as organizações possam - ou se empenhem em - impor uma "dada linha interpretativa" aos seus membros, elas vão, de alguma forma, tentar saber mais sobre esses sujeitos, conhecendo seus "códigos culturais", para que busquem "construir e oferecer discursos que, de alguma forma, possam neutralizar as resistências e gerar simpatia".

Portanto, pensar a comunicação organizacional é reconhecer, conforme Baldissera (2009, p.117) sua "diversidade de possibilidades e realizações", entendendo-a "como processo de construção e disputa de sentidos no âmbito das relações organizacionais" (Baldissera, 2009, p.116). Assim, para esse autor, a comunicação organizacional apresentará três dimensões em permanente tensionamento, numa relação de interdependência: a organização comunicada, que se refere aos "processos formais, e até disciplinadores, da fala autorizada", com o objetivo de obter reconhecimento público, legitimidade para seus processos e também "autoelogio" (Baldissera, 2009, p.118); a organização comunicante, representando "todo processo comunicacional que se atualiza quando, de alguma forma e em algum nível, qualquer sujeito (pessoa, público) estabelecer relação com a organização" (Baldissera, 2009, p.118); e a organização falada, cuja esfera refere-se aos "processos de comunicação informal indiretos [...] que se realizam fora do âmbito organizacional e que dizem respeito à organização" (Baldissera, 2009, p.119).

De modo mais específico, pensar as categorias analíticas da teoria do discurso de Laclau e Mouffe (1987) para problematizar as dimensões da comunicação organizacional de Baldissera (2009) torna-se gesto relevante à investigação dos contextos organizacionais do cooperativismo de crédito rural solidário, a partir dos processos de incorporação forçada de tais organizações em um único sistema financeiro nacional.

\section{METODOLOGIA}

A pesquisa que deu origem a essa discussão foi realizada com a Cooperativa de Crédito Rural com Interação Solidária de Tombos (Cresol Tombos), cuja organização jurídica compreendia, em 2015, a sede e um posto de atendimento no próprio município e outras cinco unidades instaladas nos municípios de Alto Jequitibá, Divino, Espera Feliz, Santana do Manhuaçu e Simonésia. Em março de 2015, essas sete unidades somavam 3.535 associados, em uma área de abrangência contendo 23 municípios distribuídos nos estados de Minas Gerais, Espírito Santo e Rio de Janeiro (Martins, 2016; Silva, 2010). 
Nesse contexto, a Cresol Tombos, fundada em 2003 (como Ecosol Tombos), cumpria função social inegável ao permitir 0 acesso de inúmeros agricultores, alijados de bancos comerciais e de outras cooperativas de crédito, a produtos e a serviços financeiros. Entretanto, a partir da incorporação ao Sistema Cresol, em 2008, questionamos: que práticas articulatórias produziram campos discursivos em torno das identidades da cooperação e da solidariedade no âmbito de tais cooperativas? Que indícios discursivos em tais práticas anunciam um novo contexto interacional entre a cooperativa e os agricultores?

Para isso, no ano de 2015, foi realizada uma pesquisa de campo, pautada por: 1) observação não-participante; 2) entrevistas semiestruturadas; e 3) diário de campo - procedimentos voltados a identificar a emergência de práticas articulatórias tanto na organização comunicada quando na organização comunicante. Tais instrumentos foram mobilizados em dois momentos distintos: 1) Em março de 2015, com a realização de observações de momentos coletivos (pré-assembleias e assembleia geral ordinária); e 2) Entre junho e julho de 2015, com a realização de 22 entrevistas - com associados, agentes comunitários de desenvolvimento e crédito, diretores e representantes da Base de Serviços de Minas Gerais (Baser Minas), em diferentes municípios.

Especificamente para a discussão e os resultados apresentados, selecionamos: 1) a parte final das entrevistas semiestruturadas - na qual solicitamos a definição de uma cooperativa de crédito rural solidária; 2) narrativas construídas a partir da observação das pré-assembleias e da Assembleia Geral; 3) transcrições das falas de diretores e representantes do Sistema Cresol durante esses momentos; e 4) anotações do diário de campo.

\section{RESULTADOS E DISCUSSÕES}

Inicialmente, foi possível identificar um discurso do Sistema Cresol, via diretores, funcionários e representantes da Baser Minas, cujo objetivo principal era provocar simpatia frente aos agricultores. Nesse contexto, o campo discursivo do cooperativismo de crédito rural solidário vê-se "atravessado" por um discurso autorizado, que é também o discurso do sistema financeiro nacional e, nesse atravessamento, as organizações que o compõem tendem, em algum momento, a incorporar determinados elementos ao seu campo discursivo, como resíduos desse discurso, com significados muitas vezes contrários à sua proposta, alterando sua prática organizacional e, consequentemente, (re)moldando sua identidade, conforme demonstra a fala seguinte:

[...] a Cresol não tem medido esforços, no nosso dia a dia, pra que a gente possa tá levando todos esses serviços, fazer com que nós tenhamos cooperados cada vez mais conscientes, cooperado cada vez mais participativo. E é dessa forma que a gente acredita que o cooperativismo vai avançar cada vez mais na nossa região. E já tem dado resultados, pelo grande número, o grande crescimento que as cooperativas Cresol hoje têm na nossa região da Zona da Mata. Não é à toa que hoje somos o sistema bancário que mais cresce [...]. Números mostram isso, né? (informação verbal) ${ }^{4}$

Conforme afirma Mendonça (2009), sentidos que são produzidos no âmbito de um interior discursivo encontram-se limitados "pelo exterior antagônico, supondo-se, assim, que o primeiro nunca poderá articular elementos do segundo sem que isso altere radicalmente suas estruturas" (p.162). Contudo, em tese, uma cooperativa não poderia representar o exterior antagônico a outra, uma vez que essas organizações surgem como uma proposta de resistência a um modelo econômico e social que exclui muitos sujeitos do mercado de trabalho. Por outro lado, as cooperativas se constituem a partir de valores que orientam grupos sociais específicos, inseridos em contextos socioeconômicos igualmente característicos e, por esse motivo, moldam sua atuação de acordo com tais peculiaridades, ainda que sejam regidas pelo mesmo conjunto de princípios orientadores (Schröder, 2005).

4 Comunicado realizado na Assembleia Geral Cresol Tombos, Tombos, 2015, grifo nosso. 
É preciso compreender que os elementos presentes nessa fala oficial representam também os interesses dos agricultores associados. Entretanto, dado o contexto de incorporação por lógicas financeiras centralizadoras, configuram-se em elementos de um discurso que, na prática articulatória, reúnem-se em torno de um ponto nodal em comum - a cooperação e a solidariedade -, reduzindo a polissemia acerca da realidade social em que esses sujeitos se encontram. Esse gesto, no âmbito organizacional, reduz múltiplos sentidos a um sentido instrumental/padronizado que não condiz com os diferentes significados apresentados pelos sujeitos (Figura 2).

Figura 2: Elementos, articulados em momentos, em torno de um ponto nodal que figuram no discurso da organização (discurso autorizado)

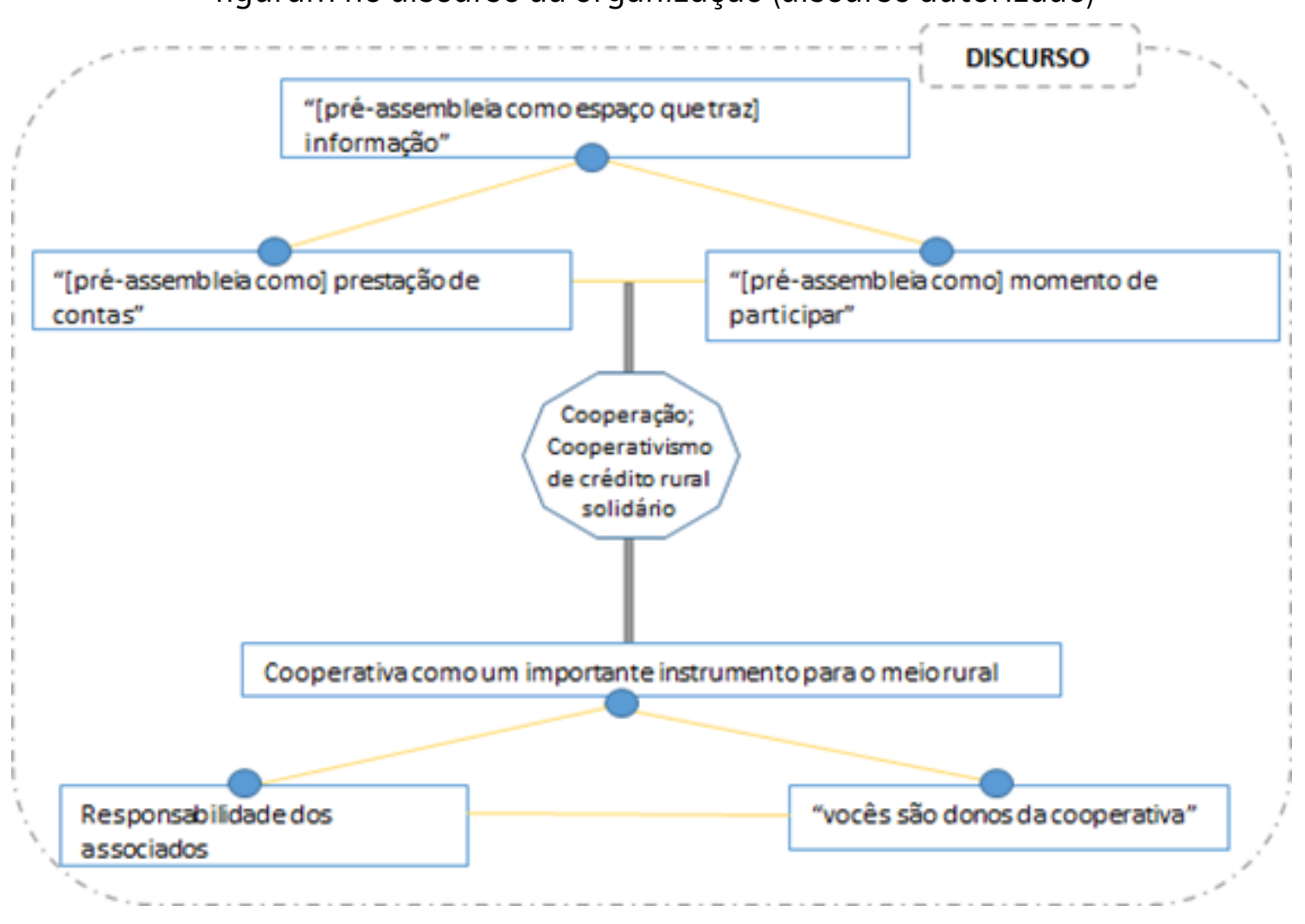

Fonte: Martins (2016)

Dessa forma, quando falamos das cooperativas hoje consideradas tradicionais, estamos nos referindo a um campo do cooperativismo que, em determinado momento, deixa-se penetrar pelos discursos produzidos por seu exterior antagônico, articulando elementos do discurso do Estado e do mercado, como a burocratização, o crescimento, o controle, a padronização, a segurança. Nesse ínterim, assumem para si, como elementos de seu próprio discurso, fatores antagônicos aos seus princípios, os quais um dia motivaram seu surgimento. Esses elementos, incorporados ao campo discursivo do cooperativismo de crédito, levam essas organizações a desvincularem-se de sua identidade de fundação. Por conseguinte, durante esse atravessamento discursivo, as cooperativas solidárias também passaram a atuar como instituições financeiras comuns, instrumentalizando o discurso da cooperação e da solidariedade:

[...] tem outros sistemas de cooperativas ligado [...] no nosso caso aqui. Esse povo se tornou um banco.... Então é relação bancocliente. A nossa relação é cooperativa-cooperado, com a missão de promover o desenvolvimento local com sustentabilidade, visando crescer a cooperativa, mas o cooperado crescer junto. Então esse é o diferencial nosso. Nós não enxergamos o cooperado como um cliente, ele é um cooperado, dono. (informação verbal) ${ }^{5}$

5 Depoimento oral de um associado da Cresol Tombos, Tombos, 2015. 
Para as cooperativas de crédito rural solidárias, esse foi o mote que lhes abriu espaço para o surgimento e motivou, em grande parte, a formação dos grupos de agricultores em torno de uma perspectiva diferenciada - e plausível - de acesso ao crédito e a outros serviços financeiros, pois aqueles que não conseguiam acessar o sistema bancário tradicional procuravam os sistemas solidários. Entretanto, seguindo estritamente os ditames legais nessas cooperativas, podemos admitir que esse campo discursivo vê-se em meio a um processo semelhante de "atravessamento", permeando suas práticas organizacionais de elementos que desestruturam suas práticas articulatórias de cooperação e solidariedade. Com a incorporação por um sistema financeiro centralizado, tais práticas tendem a deixar de ser um significante aberto aos cooperados e eles passam a ser signatários, sujeitos obedientes, seguidores da imposição de uma prática desviante de seus contextos:

Quando eu filiei na Ecosol, eu tinha, a gente tinha esse objetivo, de criar um banco do povo, onde a gente ia mandar no nosso dinheiro, né, entendeu? A gente ia ter aquele... porque o banco é uma coisa muito burocrática, né. Cê vai ter um empréstimo mais rápido, ali a gente ia ter as nossas decisões. Aí depois foi ampliando como eu tô te falando [...] mas só que o nosso objetivo acabou. Infelizmente o sonho não é esse mais. A Ecosol, a economia solidária, fugiu. Acabou com a entrada da Cresol e agora cooperativa, já não é mais o que a gente queria. (informação verbal) ${ }^{6}$

Dessa forma, podemos perceber que as cooperativas de crédito rural solidárias tendem a instrumentalizar, em falas autorizadas, o discurso da cooperação quando assumem práticas articulatórias institucionais advindas do sistema financeiro nacional ao mesmo tempo em que tentam construir uma precária simpatia com seus cooperados. Entretanto, estes últimos podem perceber as alterações no campo discursivo em função das novas rotinas instituídas, emitindo falas desautorizadas que evidenciam a incapacidade das novas práticas articulatórias em produzir uma hegemonia discursiva mínima em torno da cooperação e da solidariedade. Se a cooperação e a solidariedade funcionavam como cortes antagônicos em diferenciação às cooperativas de crédito tradicionais, tais elementos perdem seus sentidos fundantes, gesto que, em contextos interacionais, pode insinuar a exclusão de agricultores que, historicamente, já se encontram excluídos de vários sistemas financeiros.

\section{CONSIDERAÇÕES FINAIS}

Este texto teve como propósito principal examinar como a cooperação e a solidariedade são tensionadas em práticas articulatórias nos contextos organizacionais do cooperativismo de crédito rural solidário. Para isso, foram investigados campos discursivos da cooperativa Cresol Tombos, em Minas Gerais, após a incorporação ao Sistema Cresol, motivada por lógicas de centralização prescritas pelo BCB. A partir da análise apresentada, tendo como base a Teoria do Discurso de Laclau e Mouffe (1987) e a noção de comunicação organizacional de Baldissera (2007, 2009, 2014), o trabalho revela, como resultados, o quanto práticas articulatórias da cooperação e da solidariedade, no âmbito de tais cooperativas forçadas à incorporação, passam a ser guiadas por lógicas de instituições financeiras tradicionais, opostas aos próprios princípios do cooperativismo de crédito rural solidário.

De tal sorte, as análises demonstraram que o sentido da cooperação e o princípio da solidariedade deixam de ser elementos inerentes ao campo discursivo da cooperativa, tornando-a passível de operar como uma instituição financeira comum/comercial. Além disso, na prática organizacional do cooperativismo de crédito rural solidário, é preciso contornar tensionamentos que vão além do que é institucional, pois, por um lado, existem as normas que essas organizações precisam cumprir e se materializam no discurso formal; por outro lado, há a compreensão dos associados sobre como deveria ser a atuação dessas organizações, fundamentadas em princípios e valores específicos do cooperativismo.

6 Depoimento oral de um associado da Cresol Tombos, Tombos, 2015. 
Assim, se a cooperação e a solidariedade são vivências inerentes ao cotidiano dos agricultores associados, mas não são, de alguma forma, institucionalizadas como práticas para a Cresol Tombos, isso pode ocasionar o silenciamento dos sujeitos, num campo discursivo cuja disputa de sentidos tende a não os considerar como forças legítimas em ação. Contudo, essa disputa também pode ser uma forma de autopercepção e de ressignificação de sentidos perdidos no campo de discursividade da cooperação e da solidariedade, pelo contraste das identidades agregadas. Dessa forma, ainda que tais sujeitos possam ser silenciados nos âmbitos da organização comunicada, alguns dentre eles podem perceber os novos lemas discursivos do cooperativismo de crédito rural solidário em contextos da organização comunicante, nos quais a cooperação e a solidariedade expõem uma prática articulatória cujos tensionamentos impedem sua presença nos pontos de identificação dos novos discursos organizacionais, estabelecidos pelo BCB.

As evidências apresentadas no âmbito das organizações comunicada e comunicante insinuam, portanto, a emergência de relações tensas entre associados e corpo gestor, anunciando um cenário problemático à legitimidade pública, sobretudo por revelar a instituição de novas rotinas que tendem a excluir os agricultores para os quais tais cooperativas foram criadas. Assim, esta pesquisa demonstra uma contundente tendência de descolamento de elementos em práticas articulatórias que produzem campos discursivos oficiais desvinculados dos cotidianos dos associados - práticas intensificadas por significantes que animam organizações de crédito tradicionais. Um forte dado de tal descolamento é o fato de que, desde 2017, passados alguns anos da realização de tal pesquisa, deixa de existir, no cenário institucional do cooperativismo de crédito, a terminologia "rural solidário", a partir de uma modificação na classificação das cooperativas presente na Resolução BCB n04.434, de 20157 (BCB, 2015).

Nesse contexto, os dados aqui analisados revelam a historicidade de campos discursivos que, num primeiro momento, aproximam a cooperação e a solidariedade de significantes presentes em instituições financeiras tradicionais; e, num segundo momento, excluem, dos campos discursivos do cooperativismo de crédito, os próprios sentidos da cooperação e da solidariedade. Tal gesto tende a comprometer seriamente o acesso de sujeitos já marginalizados a produtos e a serviços financeiros, apresentando impactos severos em suas rotinas econômicas e sociais - e, em última análise, em suas próprias existências.

\section{REFERÊNCIAS}

BALDISSERA, Rudimar. Comunicação organizacional na perspectiva da complexidade. Organicom, São Paulo, v.6, n.10/11, p.115-120, 2009.

BALDISSERA, Rudimar. Comunicação organizacional, tecnologias e vigilância: entre a realização e o sofrimento. E-compós, Brasília, DF, v.17, n.2, p.1-15, 2014.

BALDISSERA, Rudimar. Tensões dialógico-recursivas entre a comunicação e a identidade organizacional. Organicom, São Paulo, v.4, n.7, p.228-243, 2007.

BCB. Resolução $n^{0}$ 4.434, de 5 de agosto de 2015. Dispõe sobre a constituição, a autorização para funcionamento, o funcionamento, as alterações estatutárias e o cancelamento de autorização para funcionamento das Cooperativas de crédito e dá outras

7 Desde agosto de 2020, as cooperativas de crédito vinculadas ao Sistema Cresol, em Minas Gerais, estão reunidas sob a denominação única de "Cresol Minas Gerais" - de modo que não existe mais o nome Cresol Tombos. Essa fusão ampliou a área de abrangência para 18 (dezoito) municípios ao leste do estado, além de alguns municípios no interior do estado do Rio de Janeiro, dada a proximidade geográfica. 0 número de associados ativos na Cresol Minas Gerais, em outubro de 2020, era de 18.299 pessoas. 
providências. Brasília, DF: Banco Central do Brasil, [2016]. Disponível em: https://www.bcb.gov.br/pre/normativos/busca/ downloadNormativo.asp?arquivo=/Lists/Normativos/Attachments/48507/Res_4434_v1_0.pdf. Acesso em: 30 abr. 2021.

BITTENCOURT, Gilson Alceu. Cooperativas de crédito solidário: constituição e funcionamento. 2.ed. Brasília, DF: NEAD; ADS; CNDRS; MDA, 2001.

BRASIL. Presidência da República. Casa Civil. Lei Complementar n¹30, de 17 de abril de 2009. Diário Oficial (da) República Federativa do Brasil, Brasília, DF, 17 abr. 2009. Disponível em: http://www.planalto.gov.br/ccivil_03/leis/LCP/Lcp130.htm. Acesso em: 30 jun. 2021.

BRASIL. Presidência da República. Casa Civil. Lei no 4.595, de 31 de dezembro de 1964. Diário Oficial (da) República Federativa do Brasil, Brasília, DF, 31 dez. 1964. Disponível em: http://www.planalto.gov.br/ccivil_03/leis/L4595.htm. Acesso em: 30 abr. 2021.

BRASIL. Presidência da República. Casa Civil. Lei n-5.764, de 16 de dezembro de 1971. Diário Oficial (da) República Federativa do Brasil, Brasília, DF, 16 dez. 1971. Disponível em: http://www.planalto.gov.br/ccivil_03/Leis/L5764.htm. Acesso em: 30 abr. 2021.

BÚRIGO, Fábio Luiz. Finanças e solidariedade: uma análise do cooperativismo de crédito rural solidário no Brasil. 2006. Tese (Doutorado em Sociologia Política) - Centro de Filosofia e Ciências Humanas, UFSC, Florianópolis, 2006.

FERREIRA, Fábio Alves. Para entender a Teoria do Discurso de Ernesto Laclau. Espaço Acadêmico, Maringá, v.11, n.127, p.12-18, 2011.

FREITAS, Alair Ferreira de. A construção social do cooperativismo de crédito rural solidário na Zona da Mata Mineira. 2011. Dissertação (Mestrado em Extensão Rural) - Universidade Federal de Viçosa, Viçosa, 2011.

FREITAS, Alair Ferreira de; FREITAS, Alan Ferreira de. Análise institucional de mudanças organizacionais em um sistema cooperativo de crédito solidário em Minas Gerais. Revista de Administração Pública, Rio de Janeiro, v.47, n.4, p.999-1020, 2013.

LACLAU, Ernesto; MOUFFE, Chantal. Hegemonía y estrategia socialista: hacia una radicalización de la democracia. Madrid: Siglo XXI, 1987.

MARTINS, Márcia Eliana. Sujeitos rurais e organizações do cooperativismo de crédito rural solidário: (des)caminhos, (im) possibilidades e (re)invenções. 2016. Tese (Doutorado em Extensão Rural) - Universidade Federal de Viçosa, Viçosa, 2016.

MENDONÇA, Daniel de. Como olhar "o político" a partir da teoria do discurso. Revista Brasileira de Ciência Política, Brasília, DF, n.1, p.153-169, 2009.

SCHRÖDER, Mônica. Finanças, comunidades e inovações. organizações financeiras da agricultura familiar: o Sistema Cresol (1995-2003). 2005. Tese (Doutorado em Ciências Econômicas) - Instituto de Economia, Universidade Estadual de Campinas, Campinas, 2005.

SILVA, Luís Gustavo Teixeira da. Ernesto Laclau (1935-2014): a trajetória de um legado às ciências sociais. Cadernos de Estudos Sociais, Recife, v.1, n.29, p.193-209, 2014. 
SILVA, Márcio Gomes. Políticas públicas de desenvolvimento rural e organizações de agricultura familiar no município de Espera Feliz-MG. 2010. Dissertação (Mestrado em Extensão Rural) - Universidade Federal de Viçosa, Viçosa, 2010.

SOARES, Marden Marques; BALLIANA, Gilson Marcos. 0 cooperativismo de crédito no Brasil. In: VENTURA, Elvira Cruvinel Ferreira; FONTES FILHO, Joaquim Rubens; SOARES, Marden Marques (coord.). Governança cooperativa: diretrizes e mecanismos para o fortalecimento da governança em cooperativas de crédito. Brasília: BCB, 2009. p.17-29.

Artigo recebido em 04.05.2021 e aprovado em 09.08.2021. 